\title{
Fatigue Evaluation of Recycled Asphalt Mixture Based on Energy-Controlled Mode
}

\author{
Tao Ma, ${ }^{1}$ Kai Cui, ${ }^{1,2}$ Yongli Zhao, ${ }^{1}$ and Xiaoming Huang ${ }^{1}$ \\ ${ }^{1}$ School of Transportation, Southeast University, Nanjing, Jiangsu 210096, China \\ ${ }^{2}$ State Engineering Laboratory of Highway Maintenance Technology, Changsha University of Science and Technology, \\ Changsha 410114, China \\ Correspondence should be addressed to Tao Ma; matao@seu.edu.cn
}

Received 14 April 2017; Revised 5 July 2017; Accepted 14 August 2017; Published 14 September 2017

Academic Editor: Meor Othman Hamzah

Copyright (C) 2017 Tao Ma et al. This is an open access article distributed under the Creative Commons Attribution License, which permits unrestricted use, distribution, and reproduction in any medium, provided the original work is properly cited.

\begin{abstract}
The fatigue properties of asphalt mixtures are important inputs for mechanistic-empirical pavement design. To understand the fatigue properties of asphalt mixtures better and to predict the fatigue life of asphalt mixtures more precisely, the energy-controlled test mode was introduced. Based on the implementation theory, the laboratory practice for the energy-controlled mode was realized using a four-point-bending fatigue test with multiple-step loading. In this mode, the fatigue performance of typical AC-20 asphalt specimens with various reclaimed asphalt pavement (RAP) contents was tested and evaluated. Results show that the variation regulation of the dissipated energy and accumulative energy is compatible with the loading control principle, which proves the feasibility of the method. In addition, the fatigue life of the asphalt mixture in the energy-controlled mode was between that for the stress-controlled and strain-controlled modes. The specimen with a higher RAP content has a longer fatigue life and better fatigue performance.
\end{abstract}

\section{Introduction}

With the service life of asphalt pavement increasing, maintenance and rehabilitation are inevitable. In addition, more and more reclaimed asphalt pavement (RAP) materials have been created. Meanwhile, with the construction cost and energy consumption increasing, the recycling of RAP in new asphalt pavement has attracted more and more attention, especially in China $[1,2]$. Many studies have proved that the successful conduction of hot recycling technology of RAP can generate recycled asphalt pavement with the same performance as that of new asphalt pavement [3,4]. However, studies also indicate that the addition of RAP can affect the fatigue durability of recycled asphalt pavement $[5,6]$. Thus, many researchers are still focusing on how to evaluate and improve performance, especially the fatigue durability of the recycled asphalt mixture.

The fatigue properties of asphalt pavement determine its design life. Asphalt pavement structural defects, especially fatigue cracks, are caused by the failure of the asphalt mixture's antifatigue properties. Therefore, fatigue properties are the key issue that researchers have focused on [7]. Traditionally, the stress- or strain-controlled loading mode is used for laboratory tests. One of the two modes is selected, according to the pavement thickness. Generally, $12.7 \mathrm{~cm}$ is regarded as the boundary thickness. If the surface layer of the asphalt pavement is thicker than $12.7 \mathrm{~cm}$, the stresscontrolled mode would be selected; otherwise, the straincontrolled mode would be selected [8]. However, with the fabrication of new pavement materials, alteration of pavement design theory, and the appearance of new failure modes, the rationale behind this classification standard has been widely questioned [9].

Fatigue tests for different gradations and different mixture components were conducted, based on the stress-controlled and the strain-controlled mode, respectively [10-12]. Results indicated that, in the strain-controlled mode, fatigue life increases as the initial modulus decreases. However, in the stress-controlled mode, the fatigue life increases as the initial modulus increases. Thus, it can be seen that the control mode plays a critical role in the evaluation of asphalt mixture fatigue properties. In view of this, many researchers only 
use one control mode to evaluate asphalt mixture properties and construct fatigue damage models considering modulus, dissipated energy, and accumulative energy [13-16]. Some studies concentrated on the differences and relations between the two control modes, trying to unify the evaluation indexes [17-20] or to convert one to another [21]. However, these studies are still confined to either the stress-controlled mode or the strain-controlled mode.

Previous research [22-26] has shown that the fatigue process of the bottom surface layer of the asphalt pavement is more related to the energy than to the stress in the stresscontrolled and the strain in the strain-controlled modes. The dissipated energy of each loading cycle remains approximately constant $[27,28]$. Thus, the energy-controlled loading mode was proposed in this study, and the method to achieve it utilized a four-point bending (4PB) fatigue test device. Thereafter, fatigue properties of the asphalt mixture with $0 \%$, $25 \%$, and 50\% RAP contents were evaluated. The test results could contribute to the establishment of a new estimation index for fatigue properties of asphalt mixtures.

\section{Theory}

During one fatigue loading cycle in a $4 \mathrm{~PB}$ test, the dissipated energy of a beam could be calculated by the following equation:

$$
E=\int_{0}^{2 \pi / \omega} F \sin (\omega t) L \sin (\omega t-\varphi) d t
$$

where $F$ is the force applied to the beam $[N], L$ is the measured beam deflection $[\mathrm{m}], \varphi$ is the phase angle between force and displacement [rad], and $\omega$ is the frequency of applied force and displacement $[\mathrm{rad} / \mathrm{s}]$.

$F$ could be determined by the product of the flexural modulus and the deflection of the beam, so (1) could also be expressed as

$$
\begin{aligned}
E & =\int_{0}^{2 \pi / \omega} S L \sin (\omega t) L \sin (\omega t-\varphi) d t \\
& =S L^{2} \int_{0}^{2 \pi / \omega} \sin (\omega t) \sin (\omega t-\varphi) d t=S L^{2} \times \pi \sin \varphi,
\end{aligned}
$$

where $S$ is the modulus of the beam.

In (2), it should be noted that $S L^{2}$ equals the energy applied to the beam in the energy-controlled mode. The phase angle $\varphi$ is a property of the material itself, which corresponds to the proportion of dissipated energy. Changes during the test are so small that they could be neglected when calculating the dissipated energy. During the fatigue test, as long as $S L^{2}$ remains constant, the energy applied to the beam could be regarded as a constant. In this way, the energy-controlled mode can be achieved theoretically.

Under the strain-controlled mode, the modulus $S$ and bottom tensile strain $\varepsilon$ of the beam can be continuously renewed by software using real-time data from the displacement sensor, which makes it possible to control the applied energy. Because the deflection $L$ is directly proportional to the bottom tensile strain of the beam $\varepsilon, \varepsilon$ can be used as the controlled index. The control theory is as follows:

$$
S_{0} \times \varepsilon_{0}^{2}=S_{n} \times \varepsilon_{n}^{2},
$$

where $S_{0}$ is initial flexural modulus of the beam, $\varepsilon_{0}$ is the initial bottom tensile strain of the beam, $S_{n}$ is the flexural modulus of the beam at Cycle $N$, and $\varepsilon_{n}$ is the bottom tensile strain of the beam at Cycle $N$.

Because of the inherent limitation of the $4 \mathrm{~PB}$ fatigue test device, the energy-controlled mode cannot be achieved directly. In the strain-controlled mode, when the strain was controlled, the modulus $S_{n}$ at Cycle $N$ could be output in real time. Accordingly, the force applied to the beam $F_{n}$ was adjusted to $F_{0} \times S_{n} / S_{0}$, to guarantee that the bottom tensile strain of the beam $\varepsilon_{n}$ at Cycle $N$ would be equal to the initial tensile strain $\varepsilon_{0}$. Referring to (3) and the theory of the strain-controlled mode, we propose a laboratory operational method, based on a $4 \mathrm{~PB}$ device, called multiple-step loading: according to the modulus $S_{n}$ at Cycle $N$, shift the bottom tensile strain of the beam $\varepsilon_{n}$ to $\sqrt{S_{0} / S_{n}} \times \varepsilon_{0}$ and then shift the force applied to the beam $F_{n}$ to $\sqrt{S_{0} / S_{n}} \times F_{0}$. Thus, the energy applied to the beam can remain constant as $F_{0} L_{0}$. Using this method, the energy-controlled mode could be achieved. In the experiment, each time the force and the strain are adjusted, the fatigue test machine should be restarted. Thus, the higher the precision requirement is, the longer the break time that will be taken. However, the fatigue damage might mitigate during the intermittence due to the asphalt selfhealing effect [29-31], which would reduce the accuracy. In this study, a $15 \%$ reduction of the beam modulus was used for the loading process, and the fracture of the beam was set as the standard of failure.

\section{Operation Method for the Energy-Controlled Mode}

A base asphalt with a penetration grade of 70 was used as a binder. Aggregates used for the mixture design were 100\% limestone, and the mineral powder was limestone powder. RAP materials were milled from the surface layer of an expressway that had been used for 10 years and showed serious pavement defects such as cracking, raveling, and rutting. These materials were subsequently then processed in a plant. Next, the RAP materials were obtained from the mix plant and used for laboratory tests. The gradation of RAP materials is shown in Table 1. The basic properties of the extracted RAP binder are shown in Table 2. A dense graded asphalt mixture with a nominal maximum aggregate size of $19 \mathrm{~mm}$ (AC20) was used as the design type of the new asphalt mixture and recycled asphalt mixture. The designed gradation of AC20 is shown in Figure 1. By using the designed gradation as the target gradation, three AC20 with RAP contents of $0 \%$, $25 \%$, and $50 \%$ were prepared, and their gradations are also shown in Figure 1. All the prepared mixtures were subjected to fatigue tests with different controlled modes, and their fatigue properties were analyzed.

The operational procedures for the energy-controlled mode were as follows. 
TABLE 1: Gradation of RAP.

\begin{tabular}{lcccccccccc}
\hline Sieving size/mm & 16 & 13.2 & 9.5 & 4.75 & 2.36 & 1.18 & 0.6 & 0.3 & 0.15 & 0.075 \\
\hline Percentage passing/\% & 100 & 96.5 & 77.2 & 48.3 & 35.9 & 20.5 & 15.1 & 10.7 & 6.1 & 4.3 \\
\hline
\end{tabular}

TABLE 2: Basic properties of binders with different RAP contents.

\begin{tabular}{lccc}
\hline Type of binder & Penetration $/ 0.1 \mathrm{~mm}$ & Softening point $/{ }^{\circ} \mathrm{C}$ & $25^{\circ} \mathrm{C} \mathrm{ductility} / \mathrm{cm}$ \\
\hline Extracted RAP binder & 31.3 & 60.6 & 7.7 \\
Virgin binder & 68.0 & 48.3 & 130.7 \\
25\% RAP binder & 60.5 & 52.1 & 90.6 \\
$50 \%$ RAP binder & 48.8 & 55.0 & 45.5 \\
\hline
\end{tabular}



$$
\begin{array}{llll}
\rightarrow & 50 \% \text { RAP content } & \checkmark & 0 \% \text { RAP content } \\
\square & \text { 25\% RAP content } & \checkmark & \text { Target gradation }
\end{array}
$$

FIGURE 1: Gradations of asphalt mixtures with different RAP contents.

Step 1 (specimen preservation). Put the specimen into the environmental chamber for preservation for no less than $4 \mathrm{~h}$ at the test temperature $\pm 0.5^{\circ} \mathrm{C}$.

Step 2 (specimen placement). Install the specimen on the $4 \mathrm{~PB}$ test device and fix it with clamps. Place the LVDT and make sure it is in contact with specimen surface. Then, adjust its position to the middle of the beam. The initial readout of the LVDT should be as close to zero as possible.

Step 3 (parameter decision). The beam should be tested under a sine wave load, $200 \mu \varepsilon$ initial strain, and a loading frequency of $10 \mathrm{~Hz}$.

Step 4 (initial strain decision). Specimens with different RAP contents have different moduli. Therefore, to ensure that the energy applied to each specimen is equal, the initial strain value should be different. The beam is first loaded under $200 \mu \varepsilon$ for 500 cycles, and the stiffness modulus in the 500th cycle is the initial modulus $S_{0}$. The initial strain $\varepsilon_{0}$ for each beam can then be calculated.

Step 5. Create a new test file on the computer, set the target strain as $\varepsilon_{0}$, and then begin loading. When the modulus of the beam decreases to $0.85 S_{0}$, stop the test.

Step 6. Repeat Step 5 with the strain target as $1.0847 \varepsilon_{0}$. Because of the asphalt self-healing effect, the modulus may increase during the break. Generally, the modulus will drop again to the level before the break after about 200 cycles. Continue to load, until the modulus drops to $0.7225 S_{0}$.

Step 7. Repeat Step 5 with the target strains shown in Table 3. Keep loading until the beam fractures.

Step 8. Add up the cycle number of each loading level. Then, the fatigue life and a diagram of the flexural stiffness modulus varying with cycle number can be obtained.

At the beginning of loading Step 1, since the initial modulus $S_{0}$ was obtained with an initial strain $\varepsilon_{0}$, the energy applied to the beam at the beginning of the first loading process could be expressed as

$$
E_{0}=a \times S_{0} \times \varepsilon_{0}^{2},
$$

where $E_{0}$ is the energy applied to the beam and $a$ is a constant.

The force applied to the beam could be expressed as

$$
F_{0}=b \times S_{0} \times \varepsilon_{0},
$$

where $b$ is a constant.

A $15 \%$ reduction in beam modulus was used for the loading process. The modulus dropped to $0.85 S_{0}$ at the end of loading Step 1 , and the energy applied to the beam dropped to $0.85 E_{0}$. The force applied on the beam dropped to $0.85 F_{0}$. Then, the device was stopped and prepared for loading Step 2. To achieve the energy-controlled mode, the energy applied to the beam at the beginning of loading Step 2 should be the same as $E_{0}$. According to (3), if $\varepsilon_{2}$ is equal to $1.0847 \varepsilon_{0}\left(1.0847 \varepsilon_{0}=\sqrt{S_{0} / 0.85 S_{0}} \times \varepsilon_{0}\right)$, the energy applied to the beam at the beginning of loading Step 2 could be $E_{0}$, the same as the first loading process. The force applied to the beam becomes $0.9219 F_{0}\left(0.9219 F_{0}=b \times 0.85 S_{0} \times\right.$ $\left.1.0847 \varepsilon_{0}\right)$. Repeating the calculation, the values in Table 3 can be obtained step by step.

\section{Comparison between Different Control Modes}

4.1. Fatigue Test Results under the Energy-Controlled Mode. The fatigue test in the energy-controlled mode was conducted using a multiple-step loading method, at a temperature of $15^{\circ} \mathrm{C}$. The size and manufacturing method of the beam, test 
TABle 3: Parameter-controlled process under the energy-controlled mode.

\begin{tabular}{lcccc}
\hline Loading step & Stiffness & Tensile strain & Load & Energy \\
\hline 1 & $S_{0} \rightarrow 0.85 S_{0}$ & $\varepsilon_{0}$ & $F_{0} \rightarrow 0.85 F_{0}$ & $E_{0} \rightarrow 0.85 E_{0}$ \\
2 & $0.85 S_{0} \rightarrow 0.7225 S_{0}$ & $1.0847 \varepsilon_{0}$ & $0.9219 F_{0} \rightarrow 0.7836 F_{0}$ & $E_{0} \rightarrow 0.85 E_{0}$ \\
3 & $0.7225 S_{0} \rightarrow 0.0 .6141 S_{0}$ & $1.1765 \varepsilon_{0}$ & $0.8500 F_{0} \rightarrow 0.7225 F_{0}$ & $E_{0} \rightarrow 0.85 E_{0}$ \\
4 & $0.6141 S_{0} \rightarrow 0.5220 S_{0}$ & $1.2761 \varepsilon_{0}$ & $0.7836 F_{0} \rightarrow 0.6661 F_{0}$ & $E_{0} \rightarrow 0.85 E_{0}$ \\
5 & $0.5220 S_{0} \rightarrow 0.4437 S_{0}$ & $1.3841 \varepsilon_{0}$ & $0.7225 F_{0} \rightarrow 0.6141 F_{0}$ & $E_{0} \rightarrow 0.85 E_{0}$ \\
6 & $0.4437 S_{0} \rightarrow 0.3771 S_{0}$ & $1.5012 \varepsilon_{0}$ & $0.6661 F_{0} \rightarrow 0.5662 F_{0}$ & $E_{0} \rightarrow 0.85 E_{0}$ \\
7 & $0.3771 S_{0} \rightarrow 0.3206 S_{0}$ & $1.6283 \varepsilon_{0}$ & $0.6141 F_{0} \rightarrow 0.5220 F_{0}$ & $E_{0} \rightarrow 0.85 E_{0}$ \\
\hline
\end{tabular}

conditions, and devices all followed the standard T07392011 test method from the Chinese specification JTG E202011 [32]. After each loading level, data such as fatigue life, dissipated energy, and modulus can be obtained. Summarizing these data makes it possible to draw the variation curves for the entire fatigue life. The variation regulation of dissipated energy, accumulative dissipated energy, and modulus is illustrated in Figures 2, 3, and 4, respectively.

As shown in Figures 2 and 3, when loading in the energy-controlled mode, there is a highly linear relationship between the accumulative dissipated energy and loading times, although the force applied and the dissipated energy during each loading level decreased. The energy applied to each beam is the same, so the curves of accumulative dissipated energy of different beams roughly coincide with each other. This confirms the accuracy of the test method. From Figure 4, it can be seen that the modulus decreases with an increase in loading times, and, as in the strain-controlled mode and the stress-controlled mode, the fatigue process of the energycontrolled mode can be divided into three periods: initial, stable, and fracture period. In addition, fatigue properties were evaluated by loading times in the energy-controlled mode. Figures 2, 3, and 4 show that AC-20 with 50\% RAP content performs best, followed by $25 \%$ RAP content, and $0 \%$ performs the worst. In addition, the poorer the fatigue properties were, the faster the material modulus reduced. The loading times of the initial period and fracture period vary little between different control modes, and the fatigue life depends greatly on the stable period. In this respect, there was no significant difference among the three control modes.

\subsection{Comparison of Fatigue Test Results under Different Control} Modes. Fatigue tests under the strain-controlled and stresscontrolled modes were conducted at a temperature of $15^{\circ} \mathrm{C}$, for comparison with the energy-controlled mode. In the strain-controlled mode, the target strain was set at $450 \mu \varepsilon$, and the test stopped when the modulus decreased by $50 \%$. The accumulative dissipated energy variation regulation during the fatigue test is shown in Figure 5. The modulus variation regulation is shown in Figure 6.

Results showed that AC-20 with 25\% RAP content had the longest fatigue life, $0 \%$ RAP content was second, and $50 \%$ had the shortest life. Figure 6 indicates that the mixture had a higher modulus when the RAP content was higher. Thus, the dissipated energy is larger if the mixture has a higher RAP content, when tested at the same strain level. Consequently,

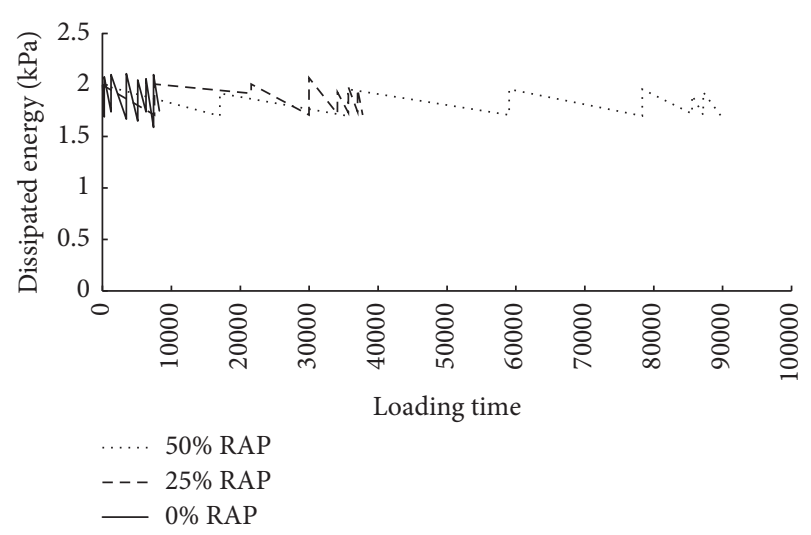

FIGURE 2: Dissipated energy variation under the energy-controlled mode at $15^{\circ} \mathrm{C}$.

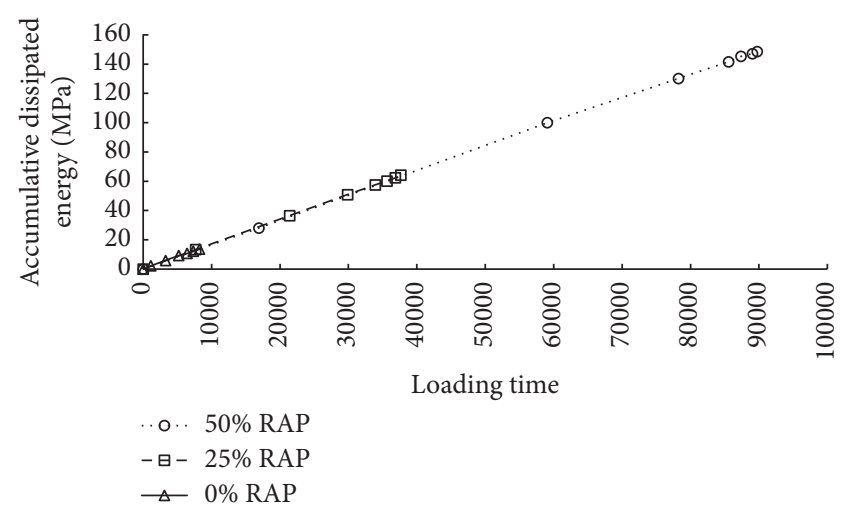

FIGURE 3: Accumulative dissipated energy variation under the energy-controlled mode at $15^{\circ} \mathrm{C}$.

in Figure 5, the slope of the 50\% RAP content is the largest. Compared with the energy-controlled mode, the growth of accumulative dissipated energy slowed down in later stages in the strain-controlled mode, resulting from a greater decrease in force. Hence, the slope of the curves decreases as loading times increase in Figure 5. Figure 6 illustrates the attenuation process of the modulus. The modulus of the $50 \%$ RAP content reduced faster, possibly because the energy applied to the beam was higher. Moreover, the fatigue life of 50\% RAP content was the shortest. However, it was not found that its fatigue properties were the poorest, because the energy applied to the beam was higher, which may result in the 
TABLE 4: Comparison of fatigue life under different control modes.

\begin{tabular}{lccc}
\hline & Energy-controlled & Stress-controlled & Strain-controlled \\
\hline $50 \%$ RAP content & 89870 & 39540 & 13590 \\
$25 \%$ RAP content & 37750 & 28450 & 62450 \\
$0 \%$ RAP content & 8270 & 1040 & 39100 \\
\hline
\end{tabular}

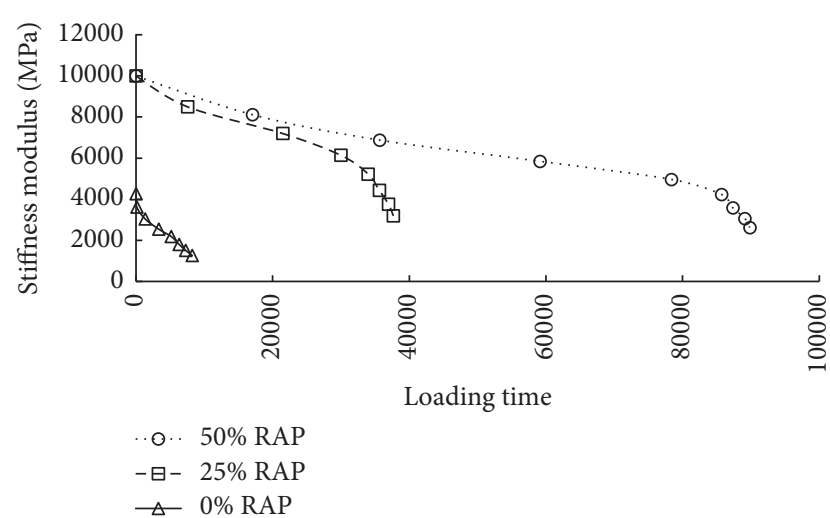

Figure 4: Flexural stiffness variation under the energy-controlled mode at $15^{\circ} \mathrm{C}$.

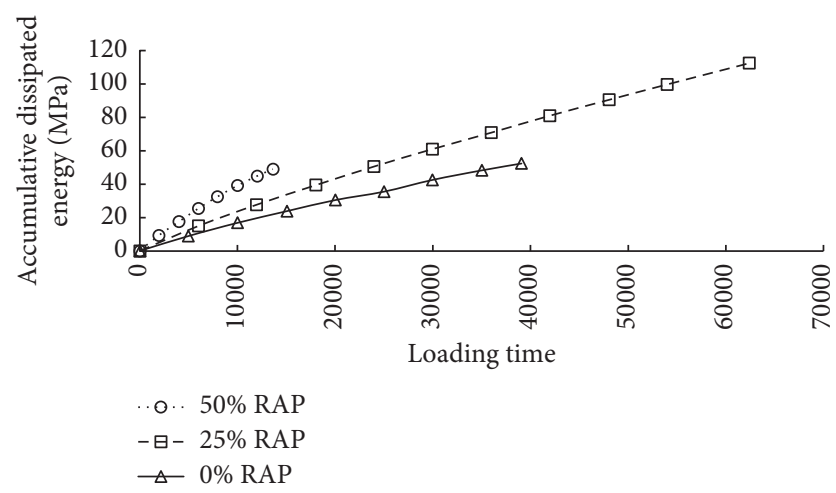

FIgURE 5: Accumulative dissipated energy variation under the strain-controlled mode at $15^{\circ} \mathrm{C}$.

shortening of the initial period and hastening of the damage accumulation. Even when put in a pavement, the material was able to bear a greater vehicle load with less strain, because of the higher modulus of the 50\% RAP content. However, this could hardly be seen from a strain-controlled fatigue test.

The force applied to the beam was $0.952 \mathrm{kN}$ in the stresscontrolled mode. Given the limitations of the test machine, neither the modulus nor the deflection could be obtained. Only the fatigue life of the three control modes could be measured. The results are listed in Table 4.

It is obvious that the higher the modulus was, the longer the fatigue life would be in the stress-controlled mode. On the contrary, a higher modulus would shorten fatigue life in the strain-controlled mode. Under the energy-controlled mode, the modulus did not affect the fatigue life. In this way, the model can better simulate the actual fatigue process of asphalt

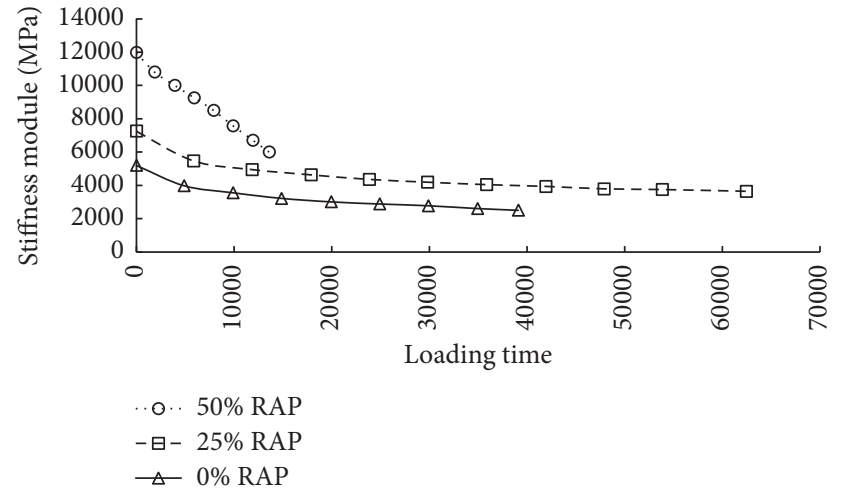

FIGURE 6: Flexural stiffness variation under the strain-controlled mode at $15^{\circ} \mathrm{C}$.

pavement, making the evaluation of asphalt mixture fatigue properties more objective.

\section{Conclusions}

(1) The working process of the test machine was analyzed using dissipated energy variation regulation during fatigue testing in the strain-controlled mode. Based on the process, a theory for the energy-controlled loading mode was proposed. A four-point-bending fatigue test device and a multiple-step loading method were used to conduct the operation steps for the energy-controlled mode.

(2) The fatigue life in the energy-controlled mode is between that of the strain-controlled and stress-controlled modes. The thickness of the asphalt pavement ceased to be the determining factor for selecting control modes. Instead, the energy-controlled mode can be used for any thickness. The dissipated energy of each loading mode should remain constant.

(3) Fatigue properties of different RAP contents were tested under the energy-controlled mode. It was indicated that the AC-20 mixture with 50\% RAP content had the longest fatigue life and the best fatigue properties. In conclusion, the higher the RAP content was, the better the fatigue properties would be. The laboratory test results matched the theoretical predictions well, while the consistency between theory and field test results should be further investigated.

\section{Conflicts of Interest}

The authors declare that there are no conflicts of interest regarding the publication of this paper. 


\section{Acknowledgments}

This work is financially supported by Natural Science Foundation of China (no. 51378006 and no. 51378123), Natural Science Foundation of Jiangsu (BK20161421), Fundamental Research Funds for the Central Universities (no. 2242015R30027), and Open Fund of State Engineering Laboratory of Highway Maintenance Technology (Changsha University of Science \& Technology, kf160104).

\section{References}

[1] T. Ma, X. Huang, Y. Zhao, Y. Zhang, and H. Wang, "Influences of preheating temperature of RAP on properties of hot-mix recycled asphalt mixture," Journal of Testing and Evaluation, vol. 44, no. 2, pp. 762-769, 2016.

[2] T. Ma, Y. Zhao, X. Huang, and Y. Zhang, "Using RAP material in high modulus asphalt mixture," Journal of Testing and Evaluation, vol. 44, no. 2, pp. 781-787, 2016.

[3] I. L. Alqadi, M. Elseifi, and S. H. Carpenter, "Reclaimed asphalt pavement-a literature review," Cracking of Asphalt Concrete Pavements, 2007.

[4] T. W. Kennedy and W. O. Tam, "Optimizing Use of Reclaimed Asphalt Pavement With the Superpave System," Asphalt Paving Technol, vol. 67, pp. 311-328, 1998.

[5] M. Tusar, E. Nielsen, F. Batista, M. L. Antunes, K. Mollenhauer, and S. Vansteenkiste, "Optimization of reclaimed asphalt in asphalt plant mixing, re-road end of life strategies of asphalt pavements," European Commission DG Research, 2012.

[6] R. Ghabchi, M. Barman, D. Singh, M. Zaman, and M. A. Mubaraki, "Comparison of laboratory performance of asphalt mixes containing different proportions of RAS and RAP," Construction and Building Materials, vol. 124, pp. 343-351, 2016.

[7] C. Shannon, A. Mokhtari, H. Lee, S. Tang, C. Williams, and S. Schram, "Effects of high reclaimed asphalt-pavement content on the binder grade, fatigue performance, fractionation process, and mix design," Journal of Materials in Civil Engineering, vol. 29, no. 2, Article ID 04016218, 2017.

[8] J. Xie and Z. Guo, "Researching on fatigue model of asphalt mixtures," Journal of Highway and Transportation Research and Development, vol. 24, no. 5, pp. 21-25, 2007.

[9] S. Lu, "Research on the selection of the fatigue test control mode of asphalt mixture," Shandong Jiaotong Keji, vol. 1, pp. 60-63, 2016.

[10] H. Wang, Z. X. Dang, L. Li, and Z. P. You, "Analysis on fatigue crack growth laws for crumb rubber modified (CRM) asphalt mixture," Construction and Building Materials, vol. 47, pp. 13421349, 2013.

[11] M. Sabouri, T. Bennert, J. S. Daniel, and Y. R. Kim, "A comprehensive evaluation of the fatigue behaviour of plantproduced rap mixtures," Road Materials and Pavement Design, vol. 16, pp. 29-54, 2015.

[12] S. Tang, R. C. Williams, and A. A. Cascione, "Reconsideration of the fatigue tests for asphalt mixtures and binders containing high percentage RAP," International Journal of Pavement Engineering, vol. 18, no. 5, pp. 443-449, 2017.

[13] L. Cong, J. Peng, Z. Guo, and Q. Wang, "Evaluation of fatigue cracking in asphalt mixtures based on surface energy," Journal of Materials in Civil Engineering, vol. 29, no. 3, Article ID D4015003, 2017.
[14] E. Fallon, C. McNally, and A. Gibney, "Evaluation of fatigue resistance in asphalt surface layers containing reclaimed asphalt," Construction and Building Materials, vol. 128, pp. 7787, 2016.

[15] X. Luo, R. Luo, and R. L. Lytton, "Energy-based crack initiation criterion for viscoelastoplastic materials with distributed cracks," Journal of Engineering Mechanics, vol. 141, no. 2, Article ID 04014114, 2015.

[16] M. Sabouri and Y. R. Kim, "Development of a failure criterion for asphalt mixtures under different modes of fatigue loading," Transportation Research Record, vol. 2447, pp. 117-125, 2014.

[17] E. Masad, V. T. F. Castelo Branco, D. N. Little, and R. Lytton, "A unified method for the analysis of controlled-strain and controlled-stress fatigue testing," International Journal of Pavement Engineering, vol. 9, no. 4, pp. 233-246, 2008.

[18] A. Bhasin, V. F. Castelo Branco, E. Masad, and D. N. Little, "Quantitative comparison of energy methods to characterize fatigue in asphalt materials," Journal of Materials in Civil Engineering, vol. 21, no. 2, pp. 83-92, 2009.

[19] M. Pasetto and N. Baldo, "Unified approach to fatigue study of high performance recycled asphalt concretes," Materials and Structures, vol. 50, article no. 113, 2017.

[20] T. Hou, B. S. Underwood, and Y. R. Kim, "Fatigue performance prediction of north carolina mixtures using the simplified viscoelastic continuum damage model," Asphalt Paving Technology: Association of Asphalt Paving Technologists-Proceedings of the Technical Sessions, vol. 79, pp. 35-80, 2010.

[21] H. Zhang, L. Shan, Y. Tan, Y. Feng, and H. He, "Comparison of asphalt fatigue characteristics under different control modes," Asphalt Pavements, vol. 1, pp. 1281-1289, 2014.

[22] D. Lei, P. Zhang, J. He, P. Bai, and F. Zhu, "Fatigue life prediction method of concrete based on energy dissipation," Construction and Building Materials, vol. 145, pp. 419-425, 2017.

[23] H. Omrani, A. Tanakizadeh, A. R. Ghanizadeh, and M. Fakhri, "Investigating different approaches for evaluation of fatigue performance of warm mix asphalt mixtures," Materials and Structures/Materiaux et Constructions, vol. 50, no. 2, article no. 149, 2017.

[24] A. Modarres and A. Aloogar, "Comparison between the fatigue response of hot and warm mix asphalts based on the dissipated energy approach," International Journal of Pavement Engineering, vol. 18, no. 1, pp. 60-72, 2017.

[25] J. Ji, Z. Suo, S. Yang, Y. Xu, and S. Xu, "Application of the dissipated energy theory to estimate the fatigue characteristics of hot and warm recycled sma mixtures," International Symposium on Frontiers of Road and Airport Engineering, pp. 1-9, 2015.

[26] A. M. Bahadori, A. Mansourkhaki, and M. Ameri, "A phenomenological fatigue performance model of asphalt mixtures based on fracture energy density," Journal of Testing and Evaluation, vol. 43, no. 1, pp. 133-139, 2015.

[27] A. Wu, Fatigue Performance Evaluation of Asphalt Mixture, Southeast University, Jiangsu, China, 2015.

[28] T. Ma, Y. Zhang, D. Zhang, J. Yan, and Q. Ye, "Influences by air voids on fatigue life of asphalt mixture based on discrete element method," Construction and Building Materials, vol. 126, pp. 785-799, 2016.

[29] X. Luo and R. L. Lytton, "Characterization of healing of asphalt mixtures using creep and step-loading recovery test," Journal of Testing and Evaluation, vol. 44, no. 6, pp. 2199-2210, 2016.

[30] Y. Hou, L. Wang, T. Pauli, and W. Sun, "Investigation of the asphalt self-healing mechanism using a phase-field model," 
Journal of Materials in Civil Engineering, vol. 27, no. 3, Article ID 04014118, 2015.

[31] W. Huang, P. Lin, and M. Huang, "Comparison of the fatigue performance of asphalt mixtures considering self-healing," International Symposium on Frontiers of Road and Airport Engineering, pp. 109-121, 2015.

[32] Ministry of Transport of the People's Republic of China, Standard Test Methods of Bitumen and Bituminous Mixtures for Highway Engineering (JTG E20-2011), China Communications Press, Beijing, China, 2011. 

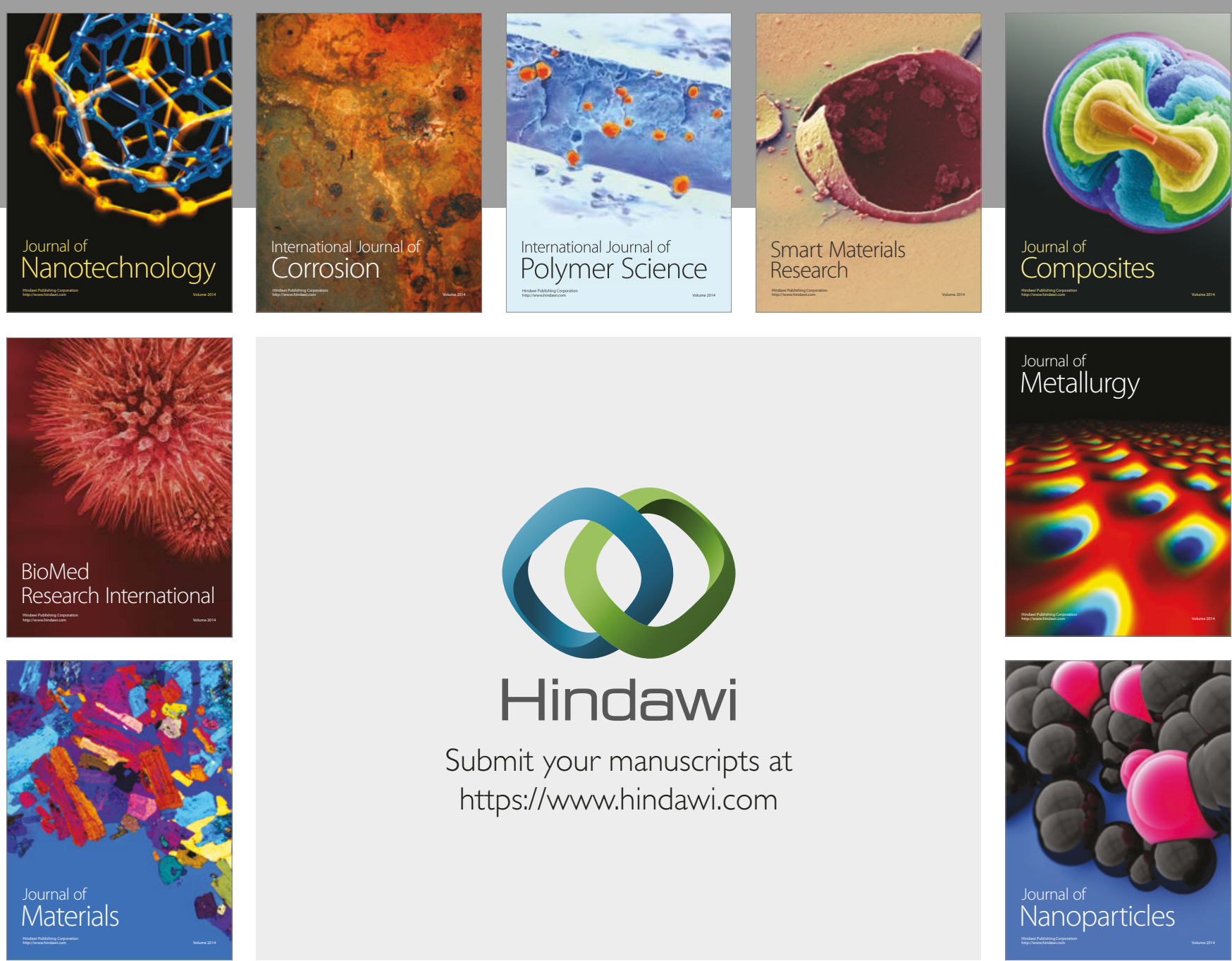

\section{Hindawi}

Submit your manuscripts at

https://www.hindawi.com


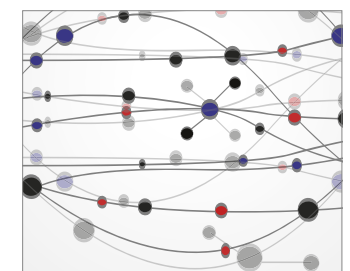

The Scientific World Journal
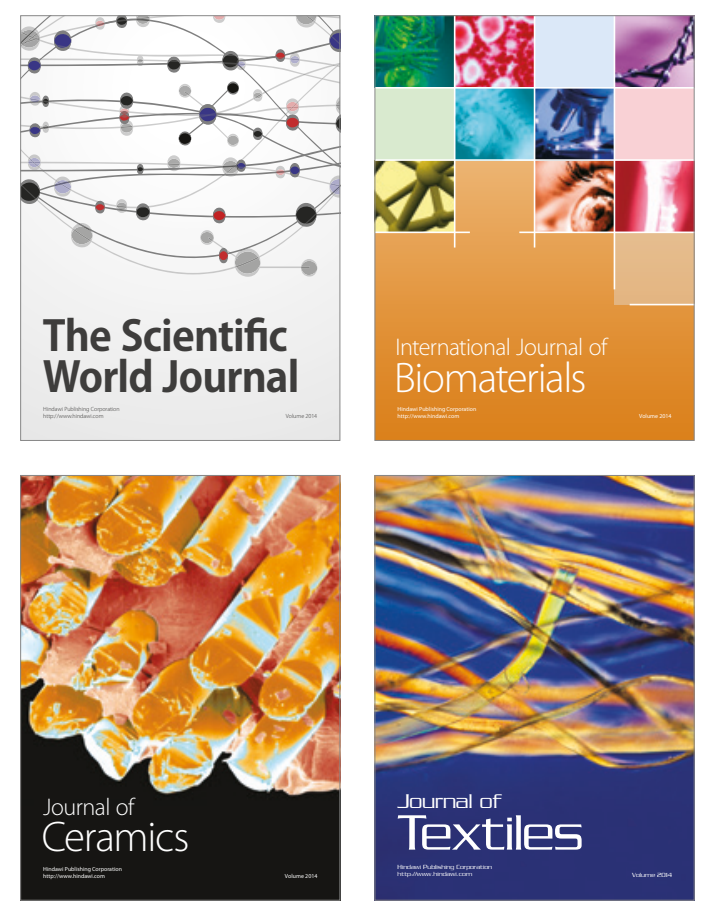